\title{
Use of Orientation Exercise towards Effective Teaching- Practice Supervision in Teacher Education Programmed
}

\author{
AbdulRahaman I. Ibrahim* \\ Kwara State College Of Education, Ilorin \\ *Corresponding author: abdulrahamanibrahim2@gmail.com
}

Received August 25, 2014; Revised September 15, 2014; Accepted September 18, 2014

\begin{abstract}
Supervision of the student teachers is essential during the teaching practice exercise; however the way or manner that some of the newly employed lecturers handle it tend to discourage the student teachers. This suggests that these categories of teachers needed an orientation exercise/seminar to put them through in their assessment and supervision. This paper therefore highlight the objective of Teaching practice (TP), functions/roles of supervisors, stages of supervision and recommendations are made towards ensuring an itch free and effective teaching practice supervision.
\end{abstract}

\section{Keywords: teaching practice supervision}

Cite This Article: AbdulRahaman I. Ibrahim, "Use of Orientation Exercise towards Effective TeachingPractice Supervision in Teacher Education Programmed.” American Journal of Educational Research, vol. 2, no. 9 (2014): 840-842. doi: 10.12691/education-2-9-21.

\section{Introduction}

The promise of education is found in the universal acceptance of the principle of education for all and adequate training of teachers to enhance effective classroom teaching. Although the principle is applied differently in different countries, each country now apply it to meet up with the current technological advancement.

In short the current innovations, the extension of the period of teaching practices exercise from 12 to 26 weeks and technological advancement in the teacher training institutions call for special orientation, workshops or seminars in order to assist the new serving teachers perform satisfactorily in accordance with the establishment goals.

Of course many of the activities involved in the T.P Supervision are not learned in the normal classroom, through a well planed orientation/seminar, all the young lecturers are expected to be assisted on how to carryout the assessment/grading and how to conduct themselves at the school of supervision.

\section{Teaching Practice Exercise}

Teaching practice exercise is an exercise or the act of teaching for a given period of time with the aim of improving the student teachers' ability to teach satisfactorily as a teacher.

Generally Teaching practice exercise involves sending/posting the student teachers out to different school specified by the school authority concerned for a period of weeks which varies from one institution to the other. Unlike in the 1990's the exercise presently is conducted for a period of twenty six (26) instead of twelve (12) weeks, and it is expected to be done at a stretch instead of being spitted into two halves.

In Nigeria it is a six credit (6c) course and made compulsory before a student is certified as a potential, qualified and professional teacher.

According to Daramola (1991), no education programme is complete without a teaching practice exercise which is meant to give the students experience towards becoming a professional teacher.

\section{Objectives of Teaching Practice}

Before the introduction of teacher training institution, in some countries, Schimmels (2009) argued that the study of lesson plan strategies began in America in the late 50's, teachers were using Catechismal method. When the desired change in instructional process was not forthcoming, Edward Scheldon (1962) then discovered the Pestalozzi approach to lesson plan presentation in Canada.

According to Schimmels (2009) after several search for a more scientific approach to teacher training, in the 90's Herbart introduced what is referred to as Herbatian approach which calls for the evaluation of the lesson plan critically, the five steps in the Herbatian approach include

(a) introduction

(b) presentation,

(c) application

(d) generalization/summary and

(e) evaluation.

As stipulated in the National policy on education (FRN, 2004), the teaching practice should be practical oriented and tailored towards the production of highly motivated, 
conscientious and efficient classroom teachers. Among the objectives of teaching practice are :

1. Helping the student teachers to develop positive attitude towards the teaching profession.

2. giving the student teachers the opportunity to observe and study learners as well as to develop his/her own ways of working with them.

3. Providing the opportunity and guidance in a school setting for a student teacher to develop his/ herself professional competencies and personal characteristics, knowledge and skills of a teacher.

4. providing student teachers with the opportunity to identify the strengths and weaknesses of their knowledge in the subject matter..

5. exposing student teachers to real life classroom experiences under the supervision of qualified and trained professional teachers.

\section{Functions/Roles of a TP Supervisor}

To achieve the above objectives, it means that apart from the possession of a recognized teaching qualification or having cognate experiences in teaching, each TP supervisor is expected to have good mastery of his/her subject, be humble, fair, competent and show a total commitment to the TP exercise.

In all the tertiary institutions, supervision of the student teachers is usually carried out by the teachers in that institution. According to Good (1945), supervision has to do with all efforts designed for the school officials toward providing leadership to teachers, with the intention of improving classroom instruction. Although it is a matter of emphasis, unlike "fault finding" or authoritarian inspection of the colonial period, the term supervision and Inspection are often used interchangeably.

What goes on in the T.P. is more of supervision rather than Inspection because the kinds of feedback to be given in the supervision is aimed at assisting the student teachers to improve on their teaching. According to Ijaiya (1991), supervision has to do with the process whereby the supervisor personally visit a classroom to observe the teaching-learning process for the purpose of assisting the teacher to improve on his/her competence or to enhance learners' learning and attainment of educational objectives.

Therefore, since the lecturers or supervisors are responsible to the Head of the institution, or his representatives, as the case may be, they are expected to conduct themselves as they will receive the greatest share of the praise for the success of the exercise or get blamed for its failure. Apart from that, the supervisors are expected to be firm in their dealings with the student teachers and maintain cordial relationship with the participating schools and the community to which they are posted.

Finally, all the supervisors are expected to be conversant with the latest development in educational practices and teaching practice schedules, be more polite in dealing with his/her colleagues and be fair to all as he evaluates the student teachers during the lesson presentation.

\section{Stages of Supervision}

For effective supervision, three major stages are identified. Namely: preparatory/Pre-observation, assessment/ observation, and feedback/post-observation.

a. preparatory /pre-observation stage: At this stage, the supervisor simply collect the student teachers' lesson plan for vetting before the commencement of the actual teaching. The purpose is to access the adequacy of the lesson/plan in relation to the objective of the lesson.

b. assessment/observation stage: this aspect deals with the observation of the actual presentation or teaching and the award of marks based on performance in each of the skills identified in the section of the assessment forms.

Marks are allocated on

1. lesson presentation.

2. mastery of the subject matter.

3. effective use of instructional materials.

4. classroom control and management.

5. effective communication.

6. appropriate evaluation technique.

7. teacher's personality or mode of dressing.

In each of these areas, the supervisor should be thorough and fair in awarding marks and ensure that each student teacher shows good mastery of the subject matter, select appropriate teaching method and instructional materials, arouse students' interest and maintains class control as well as present lesson logically before any one of them is awarded high marks.

c. feed back/post-observation stage: This usually takes place at the end of the entire supervision exercise during the day. At this period, each or all the student teachers assessed are gathered together for briefing, with the intention of showing each student teacher his/her area of strengths or weaknesses, generally for improvement. Where the time or population of the students do not permit meeting on an individual basis, group conference as a means of providing feedback is recommended.

\section{Recommendations: Hints on Successful Supervision}

To educate a man in mind, theoretically and not in morals and practice is to educate a menace to society. Considering the fact that the majority of the students on teaching practice have little or no experience about teaching, the supervisors need to change their perceptions and expectations concerning purpose of monitoring and supervision. They are expected to assist these studentteachers where necessary and to intimate them with the challenges and problems that are associated with the teaching profession.

Below are the major factors to be considered for successful supervision exercise:

a. all the enquiry should be directed to the committee (Teaching practice Coordinate) assigned to do the students' posting, they too should be up and doing and ensure that the posting lists for the students and the supervisors are ready and given to them on schedule or without delay.

b. although it is the responsibility of the college management, adequate arrangement for transportation 
is necessary for the supervisors so as to assist them in getting to their places of assignment.

c. for a successful posting and to avoid rejection of many students, there should be harmonious relationship between the college and the cooperation schools where the student teachers are posted.

d. each supervisor is expected and should be acquainted with the assessment form and should be instructed to do the scoring appropriately.

e. all the supervisors should be advised to make a courtesy visit to the school authority on entering the compound before assessing the students and should be prepared to take any responsibility for their actions during and immediately after the assessment.

f. scoring of the students teachers should not be delayed but be done at the time of the observation of the lesson to reduce subjectivity. Not only must the marks awarded be a true reflection of the students' performances, it should not be too high or too low, while the final grades awarded should agree with the comment on the assessment form.

g. all the comments based on the observation including suggestions for improvement should be written on the students' lesson notes.

h. all the used and unused teaching practice assessment forms should be returned to the College Teaching practice coordinator promptly to allow for timely collation and computation.

i. punctuality is a must for both the student teachers and the supervisors. All are expected to arrive at the venue on time while the supervisors are advised to be patient in attending to all the students attached to them, from the beginning to the end of the lesson presentation.

j. supervisors should be aware that the teaching practice is compulsory and a must for all the students, have the largest credit load and is meant to serve as a formative evaluation. It is after the exercise that the student teachers will know how or identify their areas of strengths and weaknesses.

$\mathrm{k}$. better communication is a necessity so that information flows freely from the top to the bottom or from the superior to the subordinates and the student teachers.

1. apart from knowing that the format contained three main sections, namely: basic or background information about the student assessment/evaluation criteria and general comment section, it is essential for the supervisor to indicate his/her name and append his signature in both the lesson notes and assessment forms. m. for thorough supervision, each lecturer should not be given or allocated too many students to supervise.

n. finally, supervisors are not expected to demand any form of gratification from the student teachers. It tells on the integrity of the supervisors who supposed to be their role models

\section{Conclusion}

It will be observed that the entire issues discussed in this paper are based on the fact that nothing good happens in schools, at a particular period of time, until someone reminds or informs the teachers what to do or specify what is expected of them and then monitor to see the level of performances or competencies. Of course no magic formula to solving all the problems is available, everything depends on the situation and the individual concerned.

Sincerely speaking, experience has shown that when the supervision is not carried out properly or thoroughly, some students who needed help "don't get it" and instead received a "satisfactory" or even an "excellent” mark on their evaluation. Therefore, the success of teaching practice is a collective responsibility involving all the stakeholders in education which includes the College management, cooperating schools where student teachers are posted. Finally, good organizational set up, sense of direction towards a specified goal and sense of commitment to work are necessary factors necessary for successful teaching practice supervision as well as appropriate motivation of TP supervisors.

\section{References}

[1] Adesina S; Daramola, S.O \&Jalabi; J.K (1989). A guide for students and teachers. Ibadan: Board publication Ltd.

[2] Daramola, S.O. (1991). Teaching practice and University admission for NCE graduates.Ilorin Journal of Education. 11 (1), 88-94.

[3] Federal Republic of Nigeria (2004). National policy on education (Rev. ed). Lagos: Nigeria Education Resource Council.

[4] Good, C.V. (1945). Dictionary of education. New York: McGrow - Hill.

[5] Ijaiya, N.Y.S (1991). A guide to supervision of Instruction. Ilorin: My Grace Repro. Co.

[6] National commission for colleges of Education (1996). Minimum Standard for Nigeria Certificate in Education (Rev. ed). Kaduna: The author.

[7] Orebanjo, M. A (1982), Aids to teaching practice. Ijebu Ode: National press.

[8] Schimmels, C. (2009), A white paper on lesson planning \& Facility website/resources/white paper html. 